\title{
A rede de educação, ciência e tecnologia no Contestado e a atuação para redução das desigualdades
}

\author{
Eduardo do Nascimento Karasinski ${ }^{1}$, William Douglas Gomes Peres ${ }^{2}$, Letíssia Crestani ${ }^{3}$, Juciara Ramos \\ Cordeiro ${ }^{4}$, Fernanda Zanotti5, Márcia Elizabete Schüler ${ }^{6}$
}

Resumo: Neste artigo será apresentada uma perspectiva histórica dos acentuados índices de desigualdade socioeconômica observados atualmente no estado de Santa Catarina. Em seguida, serão descritos os eventos Semana do Contestado e Congresso Nacional do Contestado, bem como, estes contribuíram para o debate sobre esta problemática. No ano de 2018, o Instituto Federal de Santa Catarina, Prefeitura Municipal de Caçador e Museu do Contestado propuseram a criação de uma agenda de atividades em rede, como metodologia de abordagem para ações de educação, ciência e tecnologia. Portanto, este projeto teve como objetivo ampliar a divulgação científica e o debate sobre as desigualdades no Contestado. A comunidade organizada foi convidada para construir e executar diversas ações. Participaram instituições públicas, instituições privadas, coletivos de artistas e representantes de grupos sociais. Desta forma, o principal resultado obtido foi o sinergismo entre as atividades realizadas e o seu impacto no público de diversos segmentos. As ações em rede demonstraram maior capacidade de alcançar principalmente estudantes da educação básica, assim como, maior cooperação dos grupos e núcleos de pesquisa das instituições envolvidas em torno do Contestado.

Palavras-chave: Ensino Fundamental; Desigualdades; Educação

\section{The network of education, science and technology in the Contestado and the action to reduce inequalities}

Abstract: This article will present a historical perspective of the accented socioeconomic inequality rates observed in the state of Santa Catarina today. Then, the events "Semana do Contestado" and "Contestado Nacional Congress" will be described and as they contributed to the debate on this problem. In 2018, the Federal Institute of Santa Catarina, the city hall of Caçador and the Contestado museum proposed the creation of an agenda of network activities as a methodology for approaching education, science and technology actions. Therefore, this project aimed to expand scientific dissemination and debate about inequalities in the Contestado. The organized community was called upon to construct and execute various actions. Public institutions, private institutions, collectives of artists and representatives of social groups participated in these actions. In this way, the main result obtained was the synergism between the activities and their impact on the public of different segments. The actions in network demonstrated a higher capacity to reach mainly students of basic education, as well as, higher cooperation of the groups and research centers of the institutions involved around the Contestado.

Originais recebidos em

12 de dezembro de 2019

Aceito para publicação em 03 de março de 2020

1 Instituto Federal de Santa Catarina (IFSC), Caçador/SC. eduardo.nascimento@ifsc.edu.br (autor para correspondência) 2 Instituto Federal de Santa Catarina (IFSC), Caçador/SC. william.peres@ifsc.edu.br

3

Museu do Contestado, Caçador/SC. leti crestani@yahoo.com.br 4 Instituto Federal Catarinense (IFC), Videira/SC. juciara.cordeiro@ifc.edu.br 5 Instituto Federal Catarinense (IFC), Videira/SC fernanda.zanotti@ifc.edu.br 6 Instituto Federal Catarinense (IFC), Videira/SC marcia.schuler@ifc.edu.br 


\section{Introdução}

\section{As desigualdades no Contestado}

A Guerra do Contestado ocorreu no sertão dos pinhais entre Paraná e Santa Catarina, passando pelo vale do rio do Peixe. O conflito deu-se entre o exército brasileiro e uma parte da população local, chamada de caboclos. O conflito bélico durou quatro anos, de 1912 a 1916. As causas foram diversas, desde a indefinição dos limites territoriais entre Paraná e Santa Catarina, que ficavam numa área rica em erva-mate e araucária, ambos de alto valor econômico; a construção da ferrovia São Paulo-Rio Grande do Sul, uma tentativa do governo para interligar o sudeste ao sul e se tornar mais presente nesse território; a exploração de terras e florestas pela empresa colonizadora norte-americana Southern Brazil Lumber \& Colonization Company, a desapropriação das terras ocupadas pela população local em consequência da legislação fundiária de 1850, dando monopólio político e econômico aos coronéis e suas enormes fazendas. Mais ainda, surgem as questões religiosas e os ideais libertários propagados pelos monges errantes (Auras, 1984; Machado, 2004; Fraga, 2012; Valentini et al., 2012; Crestani, 2017).

Os antecedentes da guerra do Contestado remetem à problemática luso-espanhola, na qual Portugal e Espanha não conseguiram estabelecer os seus limites territoriais, sendo que a região de Palmas foi reivindicada pela Argentina até 1895. Além disso, Santa Catarina e Paraná disputavam a jurisdição sobre a região das terras situadas a oeste, entre os rios Uruguai e Iguaçu. Indefinidas as fronteiras, a disputa nos tribunais se arrastou de 1851 até 1916 (Machado, 2004; Crestani, 2017).

Expropriados de suas terras, os caboclos começaram a se organizar em redutos ou cidades-santas e levantaram-se contra o poder estabelecido. Dessa maneira, o pleito foi parar nos campos. De acordo com Fraga (2012) o desenrolar da guerra no campo e nos tribunais deixou algumas marcas nas estruturas sociais, políticas e econômicas da região. Conforme Santos (2006, p. 11) a guerra do Contestado envolveu

[...] uma enorme área territorial, o movimento teve a participação de mais de 20.000 pessoas, cerca de 13 expedições militares e um número expressivo de mortos. Na prática, promoveu-se uma "limpeza étnica", libertando-se a região para as empresas criadas pelo magnata Percival Farquhar e também para outras companhias de colonização, que promoveram a implantação de inúmeras colônias. O realinhamento da ocupação do espaço foi seguido pela mudança sociocultural e econômica própria do capitalismo emergente nesta parte do país. O trem que circulava nos trilhos da SP-RS assegurava novos mercados para a produção agroindustrial, ao mesmo tempo em que aproximava distâncias e facilitava a circulação de pessoas e capitais.

A perseguição aos caboclos sobreviventes continuou nos anos seguintes à guerra, por conta dos coronéis, sendo que as consequências do conflito ainda hoje são visíveis. Pouco mais de 100 anos depois, municípios do meio-oeste catarinense possuem as situações socioeconômicas mais precárias do estado. Parecem estar abandonados no tempo. Essa realidade é explicitada por Santos (2006, p. 11):

O Contestado, porém, continua lá e também aqui [...], se quisermos olhar para lutas que continuam sendo travadas no dia-a-dia presente pelas populações espoliadas, desprovidas de capital e do futuro. Nesse caso, o Contestado serve como um providencial espelho onde podemos ver refletidas as incongruências de nossa sociedade no presente.

A guerra do Contestado ocorreu numa conjuntura que envolveu as políticas da terra no final do império e, como consequência, a deslegitimação da propriedade e da cultura dos habitantes nativos, caboclos sertanejos. Assim, o estado brasileiro amparou a apropriação desse território pelos coronéis latifundiários, sobremodo, pela corrupção e pela disputa política entre Paraná e Santa Catarina, acirrada com a exploração dos recursos 
naturais. As palavras de Borelli (1979) evidenciam a eliminação histórico-cultural do Contestado:

Enquanto levantávamos os dados episódicos para transfigurá-los numa linguagem artística, surgiram inúmeros elementos de uma riqueza extraordinária sob o aspecto cultural, cujo brilho se esmaecia nos olhos e nos costumes dos antigos moradores da região. Ilha cultural que sobreviveu incógnita, fora dos registros nacionais, porque, the foi imposto um desprezo intencional pelas elites comprometidas com seu esbulho. A orla tênue desse agente cultural, não permite mais o registro folclórico direto, seu núcleo se perdeu no poço da história, dissipado aceleradamente pelo advento das telecomunicações, que nos últimos anos o descaracterizaram. Nossas tentativas de restauração memorial uniram peças incompletas, palavras fora da gramática e um significativo silêncio.

O povo nativo que ocupava as terras Contestadas desde muito antes do conflito foi brutalmente apagado. Por isso desapareceram as características próprias do seu modo de vida. É o que se vê atualmente, quando se passa pela região. Em suas andanças pelos campos do Contestado, em visita ao antigo reduto de Caraguatá, hoje o município de Lebon Régis, Fraga (2015, p. 301) conta que:

No meu subconsciente e na inconsciência do momento vivido, sentia o barulho desencadeado durante os ataques "legais" ao reduto. Podia ver e sentir os corpos caindo em terra, os gritos, o pânico e o horror daqueles anos. Queria ver os milhares de casebres que ocupavam aquele espaço e formavam uma cidadezinha. Mas não restava nada, apenas o vazio. Tudo estava na minha memória construída com as leituras e informações obtidas numa vida de curiosidade e na tentativa de conhecer e entender este que é um dos maiores e mais expressivos momentos da história nacional. Quase tudo era representação minha.

Os resquícios dos combates ficaram nas faces dos descendentes, nas almas dos que se foram e nas práticas de sociabilidade atuais da população das cidades que compõem a região do Contestado hoje. Boa parte da região onde viviam os sertanejos antes da guerra foi objeto de ação de companhias particulares de colonização que, agindo em acordo com as autoridades públicas, lotearam antigas terras dos caboclos posseiros para descendentes de segunda e terceira geração de imigrantes europeus.

Conforme Fraga (2012, p. 23), "parece que este será o ano, do centenário da guerra do Contestado, que perpassará por muitas possibilidades de rompimento da sua invisibilidade, indo da política, passando pelas artes e chegando até os meios científicos". A partir da interiorização das instituições federais de educação, ciência e tecnologia e do aumento exponencial do acesso ao conhecimento com a popularização das tecnologias da informação, houve um recomeço para novas narrativas em torno das memórias na região do Contestado. Tem-se dessa maneira um panorama histórico que endossa as situações de desigualdade educacional, social, cultural ou econômica que são possíveis de se constatar na região do Contestado. Alguns índices socioeconômicos são detalhados a seguir.

\section{Problemática}

O município de Caçador está localizado no meio-oeste catarinense, região do Contestado, alto vale do rio do Peixe. A Agência de Desenvolvimento Regional (ADR) de Caçador é constituída pelos municípios de Caçador, Calmon, Lebon Régis, Macieira, Matos Costa, Rio das Antas e Timbó Grande, sendo estes os principais locais de batalhas durante a guerra. Esta região possui características majoritariamente voltada aos setores da agropecuária e da indústria, com participação na economia superior à média estadual, ocupando a $11^{a}$ posição no Valor Acrescentado Bruto (VAB), dentre todas as 36 regiões do estado de Santa Catarina. O município de Caçador possui o segundo maior número de eleitores do oeste do estado. 
A agropecuária é uma atividade muito importante na região do Contestado, contando com mais de 4.000 estabelecimentos agropecuários, sendo 78,2 \% familiares. A maior parte destes estabelecimentos são de pequeno porte, com 23,3 \% detendo área de terra menor que 10 hectares (Governo do Estado de Santa Catarina, 2016). As configurações territoriais decorrentes da guerra do Contestado, acrescido às migrações e imigrações, contribuíram na formatação do perfil socioeconômico e ambiental da agricultura atual, considerando inclusive a absoluta predominância, na agricultura, de famílias de ascendência europeia.

A indústria na região de Caçador tem participação superior à média estadual e oferece $44 \%$ dos empregos locais (Governo do Estado de Santa Catarina, 2016). Os principais segmentos são a indústria de transformação madeireira, metal-mecânica e transformados plásticos. A cidade de Caçador é a $7^{a}$ maior exportadora do estado, propulsionada principalmente pelo setor madeireiro, o qual é desenvolvido desde o plantio e melhoramento do pinus, até a automatização e fabricação dos sistemas produtivos pelo setor metal-mecânico. Além disso, Santa Catarina é o segundo maior estado produtor do setor de transformados plásticos, participando com 11,3 \% do mercado nacional (Associação Brasileira da Indústria do Plástico, 2017). O estado possui três grandes polos produtivos de transformados plásticos, sendo que, o terceiro maior situa-se na região do meio-oeste catarinense, onde estão instaladas cerca de 40 empresas, gerando mais de 3.000 empregos diretos, que correspondem a aproximadamente 15 \% dos empregos locais (Agência Brasileira de Desenvolvimento Industrial, 2008).

Por outro lado, considerando-se o Índice de Desenvolvimento Humano Municipal (IDHM), o município da região melhor colocado é Caçador com o índice de 0,735 (148 posição no estado) e o pior é Calmon com o índice de 0,622 (292 ${ }^{\mathrm{a}}$ posição no estado). Os indicadores mostram que a dimensão renda foi a mais determinante nos modestos resultados de desenvolvimento humano para a região. A renda domiciliar per capita da região de Caçador é de 785 reais, ficando na $31^{a}$ posição dentre todas as regiões (Governo do Estado de Santa Catarina, 2016). Considerando a região do alto vale do rio do Peixe, 43,1\% dos domicílios particulares permanentes possuem uma renda de 2 a 5 salários mínimos e 19,5\% de 1 a 2 salários mínimos (Instituto Brasileiro de Geografia e Estatística, 2011). Isto demonstra a necessidade de oferecer capacitação para geração de renda. Os indicadores de desenvolvimento humano apresentam situação muito abaixo da média do estado, tanto em relação ao IDHM, quanto ao Índice de Vulnerabilidade Social (IVS). Lebon Régis e Timbó Grande apresentam média vulnerabilidade social, enquanto que, Calmon e Matos Costa apresentam alta vulnerabilidade social, numa condição que exige atenção especial. Em Caçador, 3\% da população vive na extrema pobreza, ao passo que, em alguns municípios vizinhos, este valor pode chegar a $8 \%$ (Governo do Estado de Santa Catarina, 2016).

No que se refere ao desempenho dos alunos da educação básica, a região de Caçador se encontra em um patamar inferior à média de Santa Catarina no Índice de Desenvolvimento da Educação Básica (IDEB). A taxa de distorção idade-série no ensino médio (\%) e a taxa de abandono (\%) no ensino médio são respectivamente de 24,8 e 18,8 em Calmon, 24,3 e 14,1 em Rio das Antas e 19,8 e 11,4 em Caçador, valores muito superiores à média estadual. Deve-se considerar que apenas $74,8 \%$ dos docentes no ensino médio têm formação superior, ocupando a 35a posição dentre as 36 regiões (Governo do Estado de Santa Catarina, 2016).

Outro dos graves problemas em que a região do Contestado enfrenta é a violência contra a mulher. Em Santa Catarina, especificamente na região de Caçador, os dados apontam para um crescente e alarmante número de mulheres que sofrem violência, como aponta Córdova (2018), delegado da Delegacia de Proteção à Criança, Adolescente, Mulher e Idoso (DPCAMI) de Caçador. Cavalet e Haymussi (2019) realizaram uma pesquisa para avaliar a situação da violência contra as mulheres na cidade de Caçador. Em 2018, foram 1.215 mulheres em Caçador que sofreram violência e registraram a ocorrência em alguma das instituições locais que atendem mulheres vitimizadas. 
De acordo com o Programa de Desenvolvimento de Redução das Desigualdades Crescendo Juntos,

o desenvolvimento equilibrado das regiões é um desafio que devemos nos impor cotidianamente no processo de planejamento e implementação das políticas públicas. Para tanto, é necessário o estímulo ao desenvolvimento das potencialidades regionais, passando pela promoção da desconcentração do desenvolvimento econômico (Governo do Estado de Santa Catarina, 2016, p. 4).

Não obstante, os índices públicos de desenvolvimento são claros ao mostrar a discrepante desigualdade socioeconômica da região. Os dados estatísticos apontam que o Contestado é a região com maior desigualdade de Santa Catarina. Apesar de haver elevado desempenho econômico e um grande potencial para o desenvolvimento tecnológico, ainda persiste uma situação de alta vulnerabilidade social, em razão do elevado número de práticas desiguais. Aliado aos fatores históricos, os investimentos públicos privilegiavam as regiões litorâneas e demoraram muito na sua interiorização, deixando o Contestado com décadas de atraso. Portanto, democratizar o acesso à cultura, à ciência e à tecnologia, levando conhecimento para a comunidade, é uma necessidade fundamental de oportunidades de empoderamento e de resgate da educação, além de afirmar que, esta terra também é sujeita de direitos e de práticas que contribuem com um espaço de debates para redução dessas desigualdades.

\section{A atuação da rede de educação, ciência e tecnologia}

O projeto intitulado: "Semana do Contestado: um olhar científico para a história de um povo" foi fomentado pela chamada pública do Conselho Nacional de Desenvolvimento Científico e Tecnológico (CNPq) para realização da Semana Nacional de Ciência e Tecnologia (SNCT) de 2018. Este projeto contemplou a região do Contestado em um evento de abrangência regional, o qual teve como objetivo ampliar a divulgação científica e o debate sobre a problemática das desigualdades, pela amplitude que foi o conflito do Contestado, pela memória de um povo e pela propositura de uma agenda de reconhecimento e empoderamento regional, de modo a oportunizar maior acesso à cultura, à ciência e à tecnologia para jovens estudantes do ensino básico e para a comunidade local, constituindo-se estes como público-alvo.

\section{Metodologia}

A partir da disponibilização dos recursos, fez-se necessário o apoio popular para tornar a disseminação do conhecimento acessível, sobre a ótica do resgate de identidade, a pequenos passos, neste instante. Assim sendo, a equipe do Instituto Federal de Santa Catarina (IFSC) câmpus Caçador, conduziu os trabalhos em conjunto com: a Prefeitura Municipal de Caçador, o museu do Contestado, o Núcleo de Estudos sobre o Contestado (NEC) do Instituto Federal Catarinense (IFC) câmpus Videira, o Serviço Social do Comércio (SESC) unidade de Caçador, a Universidade Federal de Santa Catarina (UFSC) câmpus Curitibanos, a Universidade do Estado do Paraná (UNESPAR) câmpus União da Vitória, as secretarias municipais de educação da região, os grupos da sociedade organizada e outras instituições privadas da região. Foram realizados dois grandes eventos que englobaram outras dezenas de ações, sendo eles: Semana do Contestado e Congresso Nacional do Contestado.

A proposta metodológica para atingir o objetivo desejado foi baseada na criação de uma agenda de atividades em rede para educação, organizada cooperativamente entre as instituições envolvidas. Durante o período de execução deste projeto foram realizadas reuniões gerais mensais para planejar e definir o cronograma das atividades propostas. Foram criados grupos de trabalho por áreas afins com o propósito de operacionalizar as ações. Trabalhou-se com encontros semanais dos grupos no decorrer das atividades, para apresentações culturais, para oficinas e palestras, para comissão científica, para divulgação e para execução financeira. 
A avaliação do impacto dos resultados do evento Semana do Contestado foi realizada em assembleia geral com a participação dos grupos envolvidos, considerando como critério relevante o público presente nas atividades. As oficinas nas escolas tiveram avaliação específica realizada pelos oficineiros. A avaliação do Congresso Nacional do Contestado foi realizada em assembleia geral com a comissão organizadora considerando o formulário eletrônico respondido pelos participantes e o retorno técnico dos palestrantes à equipe organizadora. A avaliação por meio de assembleias considera que o discurso do sujeito coletivo é uma forma de resgatar as representações sociais obtidas a partir das opiniões ou expressões individuais. Agrupase as opiniões de sentido semelhante presentes em diferentes depoimentos, como se tratasse de uma coletividade falando na pessoa de um indivíduo.

As ações culturais incluíram sessões de exibição de documentários, exposição de pinturas e fotografias, concertos musicais e peças teatrais sobre o Contestado. As atividades foram realizadas em locais públicos com a finalidade de abranger a comunidade não escolar. Em contrapartida, pretendeu-se atuar com o público do ensino básico com ações de intervenção nas escolas públicas por meio de oficinas ou palestras, levando em consideração o processo de ensino-aprendizagem e o protagonismo discente. As oficinas possibilitam uma estratégia de ensino-aprendizagem interdisciplinar dos temas abordados. Sobretudo, proporciona ao aluno um campo de aplicação, ampliação e consolidação dos conteúdos vistos. As oficinas foram elaboradas e orientadas por colaboradores das instituições participantes e ministradas por discentes extensionistas. Desta forma, se fortaleceu o protagonismo discente, aspecto importante para o empoderamento destes estudantes extensionistas. As escolas-alvo da intervenção foram selecionadas por orientação das secretarias municipais de educação, considerando critérios como menor renda domiciliar local, maior distância do centro da cidade e maior precariedade da estrutura geral da escola. O público ouvinte do Congresso Nacional do Contestado também foi direcionado para os estudantes do ensino básico da rede pública.

\section{Resultados e Discussão}

A Semana do Contestado foi construída de forma democrática por meio de um esforço coletivo. Após diversas reuniões de organização, foi então, construída a programação do evento, mostrada no Quadro 1. A Figura 1 mostra o cartaz e o convite do evento. Ao todo, 22 instituições de Caçador e região apoiaram a iniciativa, sendo um marco de coletividade e trabalho de base, consolidando a práxis dos Institutos Federais em seu papel na educação científica e tecnológica.

A programação da Semana do Contestado contou com apresentações artísticas que retrataram a história e a cultura da região, trazendo novos conhecimentos a muitas pessoas. Não foi possível fazer um levantamento preciso do número de pessoas participantes deste evento, considerando que as ações foram realizadas em diferentes locais de livre circulação pública. Sobretudo, o principal resultado levantado por intermédio dessas ações foi a produção cultural, as quais visaram a expressão e ressignificação da identidade do Contestado.

As oficinas científicas contemplaram cinco escolas municipais da educação fundamental, além dos Centros de Referência da Assistência Social (CRAS) e dos Centros de Atenção Psicossocial (CAPS). Estas oficinas mostraram diferentes possibilidades da realidade local ao jovens participantes. Por exemplo, a oficina sobre ervasmedicinais buscou revitalizar uma prática histórica na região. A oficina de robótica levou para as escolas com menor acesso às tecnologias novas possibilidades profissionais. Sobretudo, demonstrou-se alternativas para uma crescente economia solidária, e possibilitou-se debates sobre emergentes problemáticas no Contestado, como a da violência contra a mulher. 
Quadro 1. Programação realizada na Semana do Contestado.

$$
19 / 10 / 2018
$$

Cerimônia solene de abertura da Semana do Contestado.

Lançamento do projeto "PesquisAção" e lançamento do livro "Arte e história: A Guerra do Contestado em tintas, traços, vozes, penas e pincéis" de Delmir Valentini e Rita Peixe.

Local: IFSC Caçador.

Sessão de abertura do Cine Curucaca.

Local: Salão vermelho da Estação Ferroviária de Caçador.

\section{$20 / 10 / 2018$}

Conexão UFSC e IFSC - A arte atual no Contestado.

Apresentação do concerto "Caboclos Rebeldes" e dos espetáculos teatrais "Continue Rezando" e "Bruno". Local: UFSC Curitibanos.

\section{$21 / 10 / 2018$}

Cortejo Caboclo saindo da Praça da Carroça até o Parque Central.

Grande festa de abertura da Semana do Contestado, com inauguração do Reduto do Contestado e hasteamento da Bandeira do Contestado.

Atrações: Banda "Caboclos Rebeldes", Orquestra de Cordas "Raízes do Contestado", "Tributo a Vicente Telles", com Os Guardiões do Mensageiro e "Batalha do Trem" desafio de RAP.

Mostra de Economia Solidária de Artesanato.

Local: Parque Central de Caçador.

$22 / 10 / 2018$

Oficinas de Produção Poética.

Local: Escolas municipais de Caçador.

Oficinas sobre Ervas Medicinais.

Local: CRAS e CAPS de Caçador.

Mostra de Cinema Infantil.

Local: Escolas municipais de Caçador.

\section{$23 / 10 / 2018$}

Oficinas de Produção Poética.

Local: Escola do assentamento Hermínio Gonçalves Archives de Caçador.

Oficinas sobre Ervas Medicinais.

Local: CRAS e CAPS de Caçador.

Oficina de Robótica.

Local: Escolas municipais de Caçador.

Apresentação "Alma de Contestador" do músico André Jean.

Sessão do Cine Curucaca.

Local: Salão vermelho da Estação Ferroviária de Caçador.

\section{4/10/2018}

Oficinas sobre Ervas Medicinais.

Local: Comunidade Taquara Verde Interior de Caçador.

Oficina de Robótica.

Local: Escolas municipais de Caçador.

Roda de conversa com benzedeiras.

Sessão do Cine Curucaca.

Local: Salão vermelho da Estação Ferroviária de Caçador.

$25 / 10 / 2018$

Oficina de Economia Solidária.

Realização: CESMAR.

Local: CEU das Artes, Bairro Martello, Caçador.

Mesa redonda "Mulheres no Contestado: relação, trabalho, violência e empoderamento de mulheres no campo" e "Simbolismo do Contestado" Professores da UNESPAR, coletivo feminino "Quatro Tetas" e artista João Paulo. Local: Auditório da Associação Comercial e Industrial de Caçador.

"Inspira Caçador", palestra para empreendedores.

Realização: SEBRAE.

Local: Câmara Municipal de Caçador.

Sessão do Cine Curucaca.

Local: Salão vermelho da Estação Ferroviária de Caçador. 
Quadro 1 (continuação)

\section{$26 / 10 / 2018$}

Oficina de fotografia.

Local: Comunidade Taquara Verde Interior de Caçador.

Palestras "O Contestado está em guerra: conflitos, lutas e resistências" e "Contestado: mudança e consciência histórica" Silas Fonseca; Daiane Gemelli e Everton Crema da UNESPAR.

Mostra científica de trabalhos da UNESPAR, com visitação das escolas de ensino médio de Lebon Régis.

Local: IFSC Caçador.

Oficinas científicas da UFSC.

Oficinas da Secretaria Municipal de Cultura, Esportes e Turismo.

Apresentação do Grupo de Teatro Temporá.

Apresentação "Contestado entre a vida e a morte", com o grupo Vivência de Calmon.

Rito religioso ecumênico em memória dos mortos na Guerra do Contestado.

Local: Parque Central de Caçador.

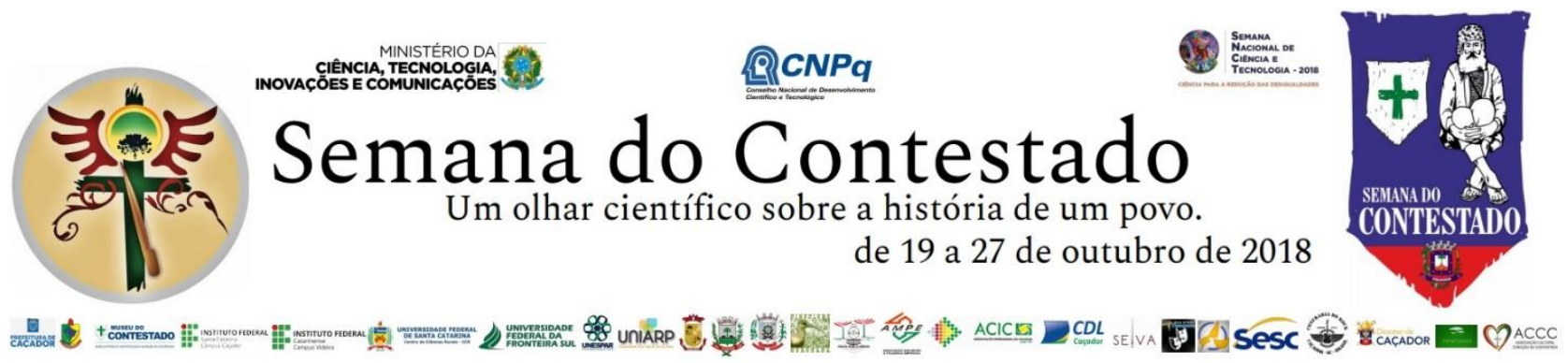

Figura 1. Arte gráfica do cartaz de divulgação e convite para a Semana do Contestado. Fonte: do próprio autor.

Com isso, pretendeu-se mostrar que, a partir da construção de uma agenda em rede de longo prazo, com práticas culturais, científicas e tecnológicas que promovam acesso ao conhecimento, pode-se atuar de forma sinérgica na redução das desigualdades de modo efetivo e atento, reduzindo fronteiras entre comunidades. Assim, faz-se com que a identidade coletiva tenha centralidade nos fatores educacionais e nas redes de pertencimento e compartilhamento de valores. De acordo com Gohn (2019, p. 68-69), a participação social deriva de uma concepção de cidadania ativa, e supõe redes de interações variadas e complexas, entre pessoas, coletivos e instituições. Desta forma, o papel das instituições é menos importante como organizadoras dos movimentos, mas de maior relevância atuando em redes de articulações, fomentando a ação coletiva, as quais suportam e criam oportunidades.

Após a conclusão do evento Semana do Contestado, a agenda de divulgação científica estendeu-se para a realização do evento chamado Primeiro Congresso Nacional do Contestado, que ocorreu em junho de 2019 no IFSC Caçador. Foi o primeiro evento de magnitude científica sobre o Contestado na história da região, sendo um evento de experimentação e também de êxito, pois reuniu pouco mais de 80 trabalhos, apresentados por estudantes desde o ensino médio a doutores referências em suas áreas de estudo. Foram mais de 1.000 participantes registrados no sistema de cadastro, superando as expectativas de público da organização do evento, como pode ser visto na Figura 2. 


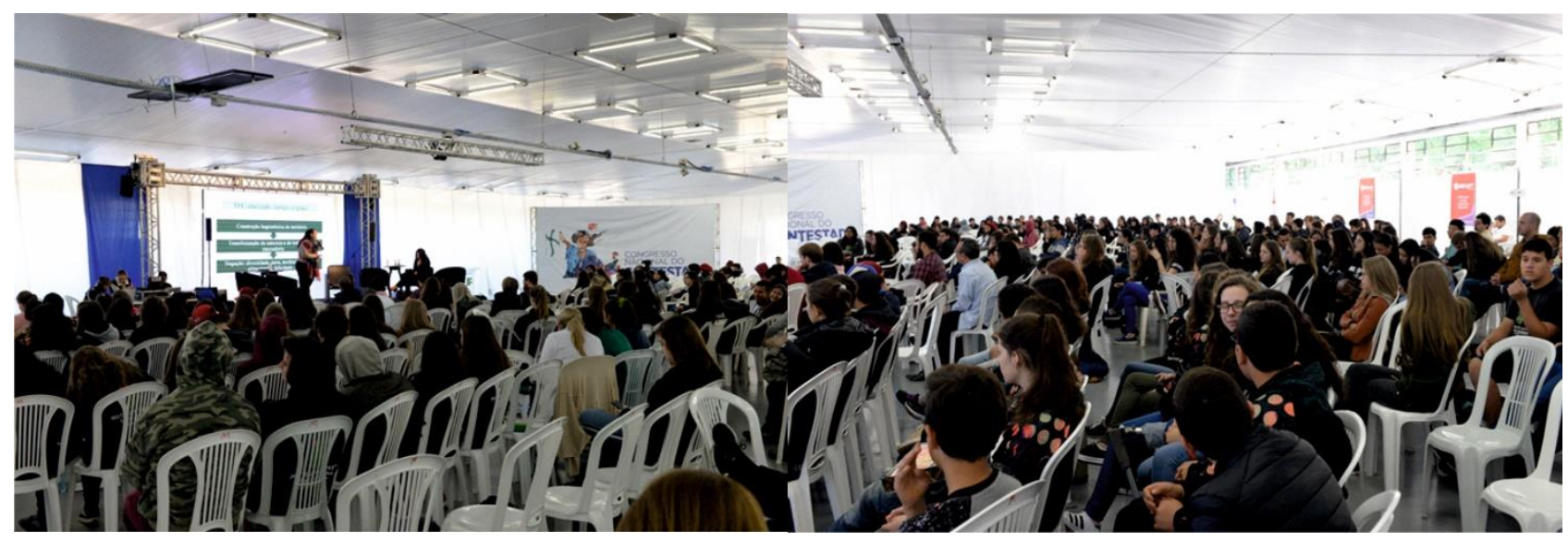

Figura 2. Fotos do Primeiro Congresso Nacional do Contestado realizado de 12 a 15 de junho de 2019, mesa de debate no salão de eventos da CDL no parque das araucárias em Caçador. Fonte: dos autores.

A programação do congresso conteve as seguintes atividades: Videoconferência com o tema "Cidades pequenas e desigualdades na América Latina" com Dr. Eduardo López Moreno, diretor de investigação e construção de capacidades da ONU-habitats; Apresentação cultural com a produção musical da banda Caboclos Rebeldes, que trabalha a identidade do Contestado; Palestra de abertura com Dr. Donaldo Schüler, livre-docente pela UFRGS e PUCRS, tradutor e autor de várias obras, entre elas "Império Caboclo", um clássico literário sobre a Guerra do Contestado; Mesa de debate com Dra. Eliane Tomiasi Paulino da UEL, Dra. Roberta Sperandio Traspadini da UNILA e Dra. Katya Regina Isaguirre da UFPR com o tema "A população originária e o território: questão agrária e as raízes da superexploração na América Latina"; Mesa de debate com Dra. Rita Inês Petrykowski Peixe do IFSC, Dra. Alcimara Aparecida Foestch da UNESPAR e Dra. Tânia Welter da UFSC com o tema "Caboclas e caboclos: cultura, arte e religiosidade no Contestado"; Mesa de debate com Dra. Márcia Janete Espig da UFPel, Dr. Alexandre Assis Tomporoski da UnC e Dr. Delmir José Valentini da UFFS com o tema "Guerra do Contestado: conflitos e transformações"; Mesa de debate com Dr. Paulo Pinheiro Machado da UFSC e Dr. Rogério Rosa Rodrigues da UDESC com o tema "Os crimes contra a humanidade e a guerra do Contestado"; Mesa coletiva formada por líderes de associações, comunidades e representantes de práticas em prol da memória e identidade cabocla, com o tema "Pontos de luz: resistência, luta e legado do povo caboclo"; Visita técnica aos locais históricos de batalhas em Lebon Régis, o coração do Contestado.

Uma exposição de pinturas com a temática do Contestado foi fixada durante o congresso, incorporada também na logomarca do evento (Figura 3). Ademais dos importantes resultados para a divulgação científica debatidos nas mesas e apresentações de trabalhos, destaca-se o lançamento do livro-jogo do Contestado, publicação didático-pedagógica sobre o tema. Ainda, destaca-se o trabalho popular de base do grupo "Coração do Contestado" de Lebon Régis, o qual articula e incentiva ações na educação infantil, na cultura e no turismo daquele município.

O Primeiro Congresso do Contestado trouxe pesquisadores com trabalhos em diversos eixos temáticos, ciência e tecnologia, população e relações étnico-raciais, patrimônio imaterial e cultural, conflitos sociais, trabalho e violências, gênero e suas reflexões, territorialidades e meio ambiente, dentre outros, caracterizando um amplo debate interdisciplinar. Desta maneira, foi um congresso inovador, pois foi um evento de divulgação científica de abrangência nacional, realizado de forma totalmente gratuita, que teve como público-alvo estudantes, principalmente da educação básica. 


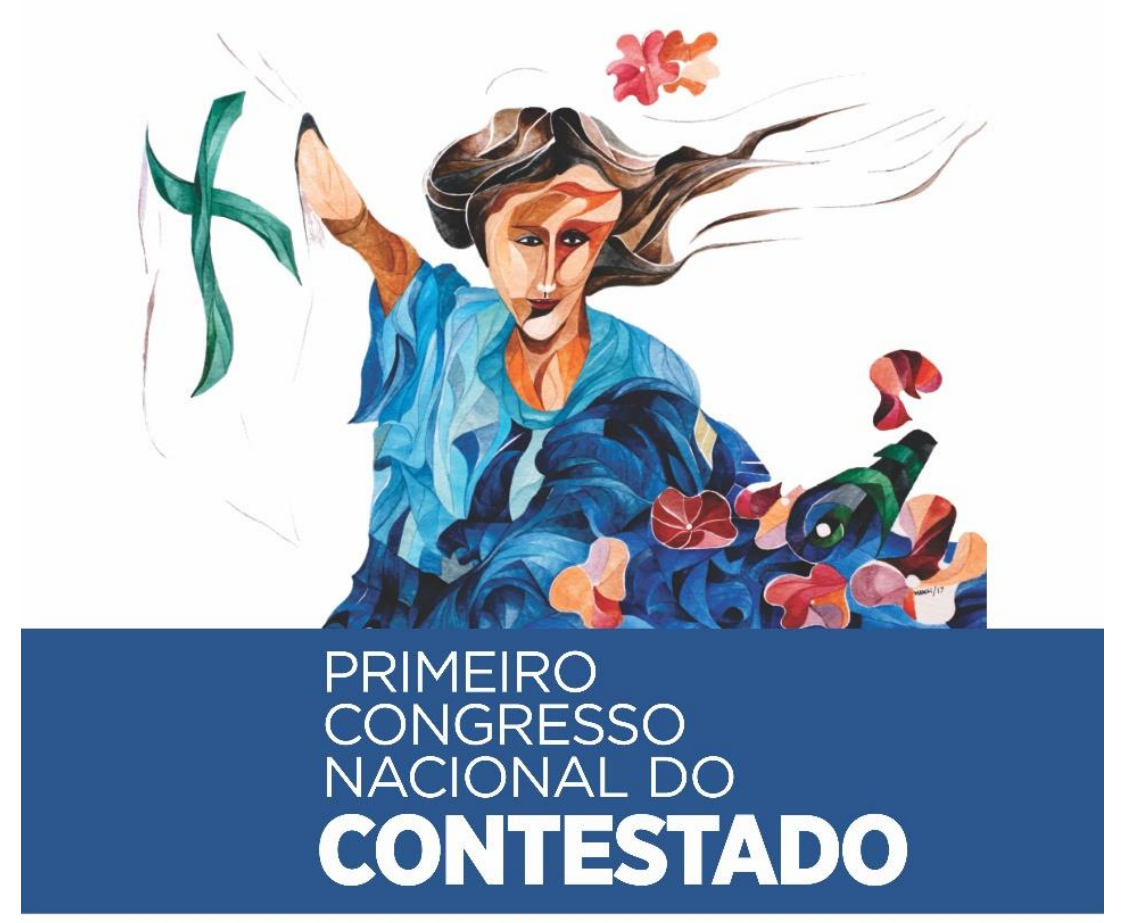

De 12 a 15 de junho no IFSC de Caçador, Santa Catarina

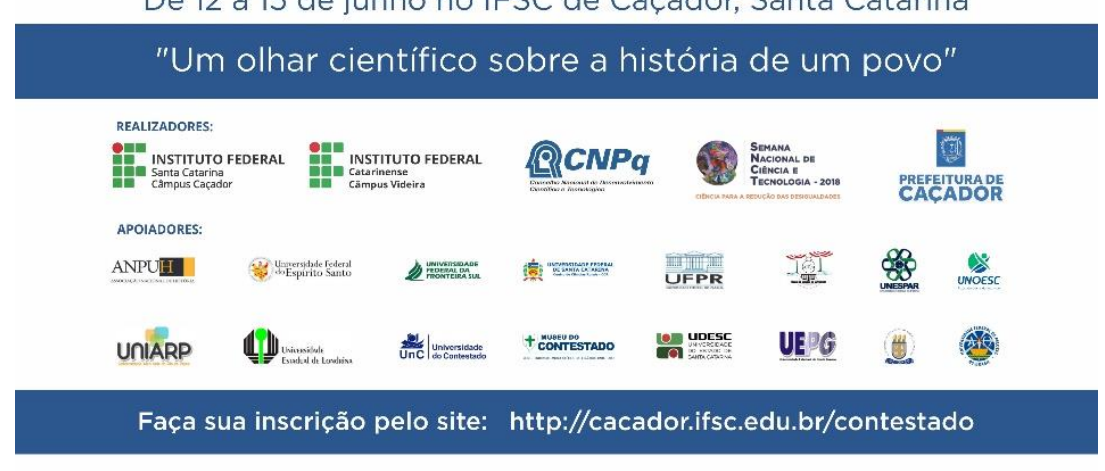

Figura 3. Cartaz de divulgação do primeiro Congresso Nacional do Contestado, imagem cedida pela artista Maní. Fonte: dos autores.

No trecho citado abaixo, contido em um relato de experiência recebido de um professor do ensino básico da rede pública, ressalta-se a importância do resgate da educação para o empoderamento e identidade dos jovens no Contestado.

Pela primeira vez tivemos, para além das pesquisadoras e pesquisadores, a participação das comunidades, dos museus, de artistas, dos alunos e alunas da rede básica de ensino e isto foi engrandecedor. [...] Ele me fez perceber que eu, enquanto professora da rede básica, posso participar junto com minhas alunas e alunos, que são herdeiras e herdeiros do Contestado, de um evento de nível internacional, que posso pretender ver as/os jovens do Contestado presentes e atuantes no desenvolvimento do conhecimento e na construção das narrativas sobre a sua história (professor Y).

A partir do pensar coletivo na construção do congresso, o resultado de maior impacto foi o sinergismo na disseminação da cultura, da ciência e da tecnologia, fortalecendo a rede de educação no Contestado. A inclusão de alunos da educação básica, que nunca tiveram acesso aos assuntos debatidos, fundamental para redução das desigualdades, é uma vez mais evidenciada na manifestação de um estudante surdo, que durante 
um dos debates agradeceu grandemente aquele momento, pois segundo suas palavras (traduzidas pelo intérprete), aquelas informações nunca tinham chegado até ele.

Em outro trecho do relato antes citado, pode-se mensurar a importância de ampliar a acessibilidade ao conhecimento para a redução das desigualdades no Contestado.

Cabe destacar que a realização do evento em Caçador foi um dos grandes incentivadores à minha
participação e a de muitas outras pessoas, visto que, enquanto professora e pesquisadora do
Contestado, residente no município de Fraiburgo, torna-se quase impossível participar de eventos a
nível nacional sobre a temática, afinal, a maior parte das atividades acadêmicas relacionadas à ele
normalmente são realizadas nas Universidades vinculadas aos grupos de pesquisa, o que exclui
territorialmente boa parte dos pesquisadores da própria região Contestada, além de tornar
praticamente inviável a participação de alunas e alunos do ensino básico nestes eventos (professor
Y).

Portanto destaca-se que criar um terreno de produção de conhecimento na região do Contestado, requer também um compromisso local para disseminação deste conhecimento. Esta rede do Contestado busca ampliar a oferta de oportunidades para debates das problemáticas das comunidades, consequentemente, ampliar o acesso ao conhecimento em vários níveis de educação.

Uma definição ampla de desigualdade dada por Costa (2019) corresponde à distância entre posições ocupadas por indivíduos ou grupos de indivíduos na estrutura social, em âmbito local ou global. Essa definição diz respeito a posições econômicas e assimetrias de poder em termos de direitos políticos, sociais e existenciais. Desigualdades, mesmo que muito profundas e claramente agrupáveis a partir de diferenças, podem ou não levar a que grupos se valham dessas diferenças para se constituírem como grupos. Assim, "as lutas por justiça existentes são sempre uma articulação contingente de certa posição na estrutura social com certo discurso sobre a diferença" (Costa, 2019, p.38).

Neste caso, as "diferenças se referem aos múltiplos grupos constituídos no processo de articular (no sentido de enunciar) as desigualdades, seja para defender suas próprias posições nas hierarquias sociais, seja para exigir uma mitigação das desigualdades" (Costa, 2019, p. 38). É preciso, dessa forma, como propõe Miskolci (2017, p.54), "lidar com as diferenças de modo a encarar as relações sociais em suas assimetrias e hierarquias, reconhecendo que a divergência é fundamental em um contexto democrático". Não são as posições estruturais em si, mas sim, sua avaliação cultural e política como justa ou injusta, que conta no processo de articulação das diferenças. Consequentemente, diferenças se tornam relevantes na medida em que, o contexto histórico e as circunstâncias conjunturais tornam acentuados o desejo de preservar ou acabar com as desigualdades existentes (Costa, 2019, p.39-43).

Segundo Arroyo (2018) a superação das desigualdades sociais pela igualdade educacional tem sido dominante no pensamento político hegemônico. Porém, cabe destacar que as desigualdades sociais são produtoras das desigualdades educacionais. Ainda persiste o pressuposto de que as desigualdades nos direitos cidadãos, de trabalho ou renda, tem como causa a falta de escolarização, de aprendizagem dos conhecimentos disciplinares e, sobretudo, dos valores de trabalho e de ordem. Por outro lado, descreve Arroyo (2018) que o direito à igualdade educacional tem como fonte a falta de reconhecimento do direito de todos como humanos, sendo a raiz das desigualdades. A superioridade ou inferioridade humana, intelectual, moral, cultural, tem levado o pensamento pedagógico a defender a superação desse paradigma de classificação pela igualdade educacional, fazendo com que aprendam a ser racionais, éticos, civilizados, os grupos minoritários, "deficientes de humanidade" e, se aprovados, reconhecidos como iguais em humanidade e em cidadania. 
Enquanto a razão humana tem natureza geral e impessoal, a sensibilidade humana tem uma afinidade pelo que é particular e individual. A lei da razão é o juízo das nossas inclinações, e quando é sentida como obrigatória e opressora tal lei, é que ela exerce uma restrição (Durkheim, 2008, p.104). Consequentemente, uma das tensões observadas nas desigualdades é entre o universal e o identitário. $O$ universal é validado independentemente dos contextos, em todos os tempos e lugares. Logo, o identitário de outros coletivos, de outras culturas não é reconhecido no universal, nem as concepções alternativas de valores, de objetivos de emancipação, de libertação e de dignidade (Santos \& Chauí, 2013, p.57-59).

Corrobora-se as definições supracitadas acerca da desigualdade, ao passo que se possibilitou à comunidade exercer o seu direito de acesso à educação, por meio da atuação em rede no Contestado. o trabalho desta rede foi dado por reconhecimento da identidade, da cidadania, dos direitos do povo caboclo, agora sem condicionantes. O resgate da educação aqui proposto não buscou igualdade no sentido de aprovar os saberes escolares, cognitivos, éticos, por conseguinte, "merecedores" do reconhecimento cidadão. Luta-se por educação, saberes, culturas, porque sabendo-se cidadãos por direito, resiste-se à segregação como desiguais.

Desigualdades são essencialmente espaciais, ou seja, são determinadas pelos espaços, pelo lugar, pois o fator que gera desigualdade é a falta de acessibilidade dos diferentes agentes de uma sociedade aos espaços, locais, tempos, culturas, conhecimentos (López Moreno, 2014). Por meio dos debates propostos, pôde-se constatar simplesmente que o Contestado tem muitas insuficiências, desde o acesso rodoviário, sendo notório a situação de extrema deterioração que se encontra a pavimentação das estradas estaduais na região. Dificuldades de acesso são ainda mais acentuadas, pela distância da região dos grandes centros e aeroportos. A ferrovia, protagonista da guerra do Contestado, desde muito não é utilizada.

Segundo López Moreno (2014) a política pública no Brasil atinge apenas $40 \%$ das desigualdades. Ao passo que $60 \%$ das desigualdades restantes continuam crescendo, acentuadamente nas cidades pequenas, distantes dos núcleos urbanos e, portanto, com baixa concentração de oportunidades. Só no Brasil, o acúmulo de capital contribui com $16 \%$ da geração de desigualdades, enquanto que, no restante da América Latina, este índice é de $3 \%$ a $4 \%$. Os custos com a infraestrutura logística e o êxodo rural, que reduz a densidade populacional nas periferias das cidades, contribuem fortemente para as desigualdades. Desta forma, mostra-se a fundamental importância que as instituições públicas têm em pensar e debater soluções para esta problemática.

\section{Considerações Finais}

A guerra do Contestado, que foi um dos maiores conflitos da história da república, possui suas mazelas recorrentes, e ainda visíveis no Contestado. Schüler (2019) encerrou sua palestra no Congresso do Contestado com a seguinte frase:

Tal qual Euclides, o caboclo histórico que não aceitou a redenção diante do padre, figura europeia a qual representava a dominação estrangeira, estamos hoje diante do século XXI, e nossa atitude precisa ser de enfrentamento ao problema da desigualdade.

O projeto "Semana do Contestado: um olhar científico para a história de um povo", representou o espírito cooperativo na construção de dois eventos, Semana do Contestado e Congresso Nacional do Contestado, de modo a promover novas organizações e mobilizações em rede da cultura, da cidadania, do direito, da ciência e da tecnologia. Diante destas ações de divulgação, popularização e resgate da educação, fomentando as demandas da comunidade local, articulou-se pensar o Contestado de forma coletiva, abrangente e contemporânea. O progresso na redução das desigualdades perpassa pela práxis das instituições. As ações ganharam sinergismo porque foram pautadas pela identidade e, assim, convergiram para o cumprimento do objetivo aqui proposto. 
Viu-se o nascer de uma rede que pretende lembrar a existência do Contestado como espaço, como território, como lugar. "Não conteste o Contestado sem saber sua razão", Borelli (1979) cantou em sua obra. Em rede, busca-se apontar um futuro menos desigual para quem vive nesse chão encharcado de sangue, e com cicatrizes de uma guerra. As manifestações artísticas e a cultura cabocla foram evidenciadas, assim como o que pesquisadores andam descobrindo, e como estão sendo construídas novas provocações sobre o Contestado. Distante de soluções definitivas, mostrou-se que a articulação em rede da comunidade, em torno de sua identidade, pode, em longo prazo, diminuir os conflitos da sociedade atual.

\section{Contribuição de cada autor}

O autor ENK escreveu o texto final; WDGP e LC foram coordenadores gerais do projeto; Todos os autores contribuíram para a execução dos eventos descritos e colaboraram com a produção textual deste artigo.

\section{Agradecimentos}

Os autores agradecem imensamente ao CNPq pelo financiamento das atividades, a todos os colaboradores e parceiros dos eventos por terem tornado possível este projeto.

\section{Referências}

Agência Brasileira De Desenvolvimento Industrial (ABDI). (2008). Relatório de Acompanhamento setorial: Transformados Plásticos. Campinas: ABDI/ Núcleo de Economia Industrial e da Tecnologia do Instituto de Economia da Universidade Estadual de Campinas - Unicamp. Recuperado de https://www3.eco.unicamp.br/ Neit/images/stories/arquivos/RelatorioABDI/transformados-plasticos vol-I dezembro2007.pdf

Arroyo, M. G. (2018). Reafirmação das lutas pela educação em uma sociedade desigual? Educação e Sociedade, 39(145), 1098-1117.

Associação Brasileira da Indústria do Plástico (ABIPLAST). (2017). Perfil 2017. [S. I.]: ABIPLAST. Recuperado de http://www.abiplast.org.br/publicacoes/perfil-2017/

Auras, M. (1984). Guerra do Contestado: A organização da irmandade cabocla. Florianópolis: Ed. UFSC/ Assembleia Legislativa. São Paulo: Cortez.

Borelli, R. J. (1979). O Contestado. Curitiba: Museu da Imagem e do Som do Paraná.

Cavalet, A. A., \& Haymussi, H. M. (2018). A violência contra mulheres na cidade de Caçador. (Trabalho de Conclusão de Curso). Caçador: UNIARP.

Córdova, L. E. M. (2018). Entrevista da rádio Caçanjurê. Caçador. Recuperado de https://portalrbv.com.br/ cacanjure/mais-de-600-ocorrencias-de-violencia-domestica-foram-registradas-em-cacador-entre-o-ano-passado-eeste-ano/

Costa, S. (2019). Desigualdade, diferença, articulação. Caderno CRH (Salvador), 32(85), 33-45.

Crestani, L. (2017). "Quem tem mói, mói, e quem não tem, mói também, e no fim, todos ficam iguais": As representações do "outro" no museu histórico e antropológico da região do contestado, de Caçador/SC. (Dissertação de Mestrado). Joinville: UNIVILLE.

Durkheim, E. (2008). A Educação Moral. Traduzido por Raquel Weiss. Rio de Janeiro: Vozes.

Fraga, N. C. (2012). Contestado em Guerra: 100 anos do massacre insepulto do Brasil. Florianópolis: Insular.

Fraga, N. C. (2015). Vale da morte: O Contestado visto e sentido "entre a Cruz de Santa Catarina e a espada do Paraná". 2a ed. Blumenau: Hemisfério Sul.

Gohn, M. G. (2019). Teorias sobre a participação social: Desafios para a compreensão das desigualdades sociais. Caderno CRH (Salvador), 32(85), 63-81. 
Governo do Estado de Santa Catarina (2016). Perfil socioeconômico ADR Caçador. [S. I.]: Governo do Estado de Santa Catarina. Recuperado de http://www.spg.sc.gov.br/visualizar-biblioteca/acoes/programa-de-desenvolvimento-ereducao-das-desigualdades-regionais/778--97/file

Instituto Brasileiro de Geografia e Estatística (IBGE). (2011). Censo 2010. Rio de Janeiro: IBGE.

López Moreno, E. (2014). Construcción de ciudades más equitativas: Políticas públicas para la inclusión en América Latina. Bogotá: CAF. Recuperado de http://scioteca.caf.com/handle/123456789/489

Machado, P. P. (2004). Lideranças do Contestado: A formação e a atuação das chefias caboclas. Campinas: Ed. UNICAMP.

Miskolci, R. (2017). Teoria Queer: Um aprendizado pelas diferenças. 2ạ ed. São Paulo: Autêntica.

Santos, B. S., \& Chauí, M. (2013). Direitos Humanos, Democracia e Desenvolvimento. São Paulo: Cortez.

Santos, S. C. (2006). O Contestado na Historiografia e na Literatura. v. 30. Florianópolis: Academia Catarinense de Letras.

Schüler, D. (2019). Palestra de abertura. Primeiro Congresso do Contestado. Caçador.

Valentini, D. J. (2000). Da cidade santa à corte celeste: Memórias de sertanejos e a Guerra do Contestado. 2a ed. Caçador: Universidade do Contestado.

Como citar este artigo:

Karasinski, E. N., Peres, W. D. G., Crestani, L., Cordeiro, J. R., Zanotti, F., \& Schüler, M. E. A rede de educação, ciência e tecnologia no Contestado e a atuação para redução das desigualdades. Revista Brasileira de Extensão Universitária, 11(1), 33-46. https://periodicos.uffs.edu.br/index.php/RBEU/article/ view/11252/pdf 